\title{
The Holistic Goals of Jewish Education
}

Gil G. Noam and Jeffrey S. Kress

$n$ this chapter, Noam and Kress bring to the fore a theme that has been present in many
of the previous chapters, namely, the need to expand our horizons beyond the cognitive. The goals of Jewish education are holistic, encompassing behavioral and affective learning outcomes, as well as cognitive. The authors begin by articulating a rationale for the importance of a holistic approach, and then discuss affordances provided by Jewish education for addressing outcomes in multiple domains. They then discuss the applicability of social and emotional learning theory and practice, with particular focus on a Developmental Domain Theory, which posits four intersecting areas of development (action, assertiveness, belonging, and reflection). They recommend that Jewish educators employ a more systematic and intentional approach to promoting and assessing outcomes in this area, and conclude by discussing the possibilities and challenge in doing so.

Discourse about schooling and its outcomes tends naturally toward mastery of academic, discipline-related, or subject matter- oriented, skills and competencies. Why can't Johnny read? Where does the United States rank among other nations in terms of math and science scores? What are the key historical events a student should know, and how can they evaluate evidence related to these? Academic achievement is tested repeatedly and on multiple levels, within classes, by state tests, and through exams that help determine college admissions.

At the same time, there is a line of discussion about the goals of education in terms of social, cultural, and affective outcomes such as preparation for citizenship, promotion of democratic ideals, and the fostering of valued virtues, dispositions, and behaviors. A variety of approaches to promoting socioaffective outcomes - such as moral education, character education, and social and emotional learning-strongly intersect, though there are details that 
distinguish each from the others. ${ }^{1}$ We will use the term whole child education (WCE) as a shorthand for an approach in which academic, social, and emotional growth are not only seen as interconnected but are also addressed with intentionality across the curriculum.

WCE manifests, broadly speaking, in two interconnected ways. "From at least the time of the Bible and Aristotle, people have wondered about humankind's potential to learn more effective ways of managing emotional experiences and social relationships." ${ }^{2}$ Whole child educators embrace their role in helping to develop that potential through actively addressing core intra- and inter-personal competencies (e.g., emotional awareness, self-control, and problem-solving) in their work.

A second thrust of WCE focuses on the conditions under which learning (in the academic, discipline- or content-specific sense of the word) takes place. For example, the Association for Supervision and Curriculum Development ${ }^{3}$ suggests that we

redefine what a successful learner is and how we measure success. A child who enters school healthy and feels safe is ready to learn. A student who feels connected to school is more likely to stay in school. All students who have access to challenging and engaging academic programs are better prepared for further education, work, and civic life. These components must work together, not in isolation. That is the goal of whole child education.

This second focus speaks to the intersection of the socio-affective and "academic" elements of learning. The whole in WCE does not imply a rejection of academic rigor, but rather a yes, and approach with multiple goals. Friction emerges, however, when it comes to the use of the limited time and resources available to educators, what outcomes to assess and how to do so, and the articulation of those values and dispositions that are shared by members of a diverse community. As the push for accountability under No Child Left Behind has led to a focus on test-scores, educators and parents have fought to protect children from a one-dimensional focus on academic achievement that they see taking away time

1 Maurice J. Elias et al., "Socioemotional Learning and Character and Moral Education in Children: Synergy or Fundamental Divergence in Our Schools?," Journal of Research in Character Education 5, no. 2 (2007), 167-82.

2 Ibid., 263.

3 Association for Supervision and Curriculum Development, Making the Case for Whole Child Education (Alexandria, VA: ASCD, 2012), 2. 
from time for interpersonal interactions, exploration, experimentation, the arts, physical education, and civic education - all of which are associated with WCE.

\section{Whole Child Jewish Education}

A religious and cultural tradition such as Judaism can be seen as engaging the "whole person," and the goals of Jewish education are framed accordingly. Far from being solely a set of beliefs or behaviors, Judaism is often conceptualized as an encompassing "mode of life." 4 This idea can be traced back to the Bible. Deuteronomy 6 alone, portions of which are included in the daily Jewish liturgy as the Shema, paints Judaism as a whole-person experience. Judaism is a religion of action and behavioral expectations (though these will differ in different Jewish communities) in which we "teach in order to do" (Deut. 6:1). Emotions are central as well; we are instructed to "love the Lord your God" (Deut. 6:5) as well as to "fear" God (Deut. 6:2). Being a Jew also means knowing about Judaism - its laws, history, etc. For example, Deuteronomy 6: 20-25, included as part of the Passover seder, suggests providing a lesson in Jewish history ("We were slaves to Pharaoh in Egypt. . .") as a response to a child's broad question about Judaism ("What are the laws. .."). Finally, we can even see an interpersonal element in this chapter, with the exhortation to "speak about" (Deut. 6:7) the commandments - presumably with an interlocutor.

A whole-person approach resonates, as well, with Martin Buber's emphasis on relationship and community, and the importance of education in facilitating entry into these. Both self-awareness and empathy are gateways into the sort of I-Thou relationships that, to Buber, contain elements of the divine. To Buber: "Every man's foremost task is the actualization of his unique, unprecedented and never-recurring potentialities, and not the repetition of something that another, and be it even the greatest, has already achieved." 5

With these Jewish thinkers and texts as a backdrop, it is not surprising that many contemporary theorists envision a multidimensional set of outcomes or goals for Jewish education-bridging the cognitive, social, affective, and behavioral. Michael Rosenak, for example, in his contribution to Visions of Jewish Education ${ }^{6}$ frames the desired outcome of Jewish education as:

4 Mordecai M. Kaplan, Judaism as a Civilization: Toward a Reconstruction of American-Jewish Life, $2^{\text {nd }}$ ed. (Philadelphia: Jewish Publication Society, 2010), 411.

5 Martin Buber, The Way of Man According to the Teaching of Hasidism (New York: Citadel Press, 1964), 16.

6 Seymour Fox et al., Visions of Jewish Education (Cambridge: Cambridge University Press, 2003), 23. 
a Jew who is animated by love of his language yet open to others, loyal to his community yet critical of its shortcomings, involved with its problems yet sensitive to ultimate concerns and responsive to the universal, proud of his identity yet secure enough not to trumpet his pride.

Likewise, the goals of Jewish education articulated elsewhere in the same volume repeatedly reference a broad range of outcomes that span developmental realms. Moshe Greenberg, for example, refers to "acceptance of the Torah as a moral guide; a way of life that creates a community; [and] a relationship to the Jewish people in all the lands of their dispersion." 7

Seymour Fox discusses the importance of educating "the entire childincluding his or her mind" which includes paying "equal attention to emotional and spiritual issues, and to the articulation and living out of Jewish values." To Fox, " $[\mathrm{k}]$ nowing is not the only precondition for doing. Man's feelings can and should be educated. Joy and happiness must somehow be correlated with appropriate behavior." 9

Finally, educational theorist Lee Shulman frames the goals of Jewish education "along three dimensions - habits of mind, habits of practice, and habits of the heart." ${ }^{10}$ The first entails a (cognitive) understanding of Jewish texts, ideas, literature, and liturgy. Habits of practice involve mastery and comfort with a variety of ritual and Hebrew language skills. Habits of the heart include the development of values, beliefs, and dispositions appropriate to a member of the Jewish community. ${ }^{11}$

Yet, even with such a strong theoretical connection to WCE, Jewish educational contexts, like those in secular education, often struggle to attend to socio-affective elements with the same intentionality and rigor with which they attend to academic outcomes. Jewish day schools, for example, must navigate a dual curriculum and powerful parent expectations for academic attainment.

7 Seymour Fox et al., "Six Visions: An Overview," in Fox, Visions of Jewish Education, 26.

8 Seymour Fox and William Novak, Vision at the Heart: Lessons from Camp Ramah on the Power of Ideas in Shaping Educational Institutions (Jerusalem and New York: The Mandel Institute and The Council for Initiatives in Jewish Education, 1997), 11.

9 Seymour Fox, "Ramah: A Setting for Jewish Education," in The Ramah Experience: Community and Commitment, ed. Sylvia C. Ettenberg and Geraldine Rosenfield (New York: Jewish Theological Seminary and National Ramah Commission, 1989), 36.

10 Lee S. Shulman, "Pedagogies of Interpretation, Argumentation, and Formation: From Understanding to Identity in Jewish Education," Journal of Jewish Education 74, sup. 1 (2008), 8 .

11 Ibid., 8 . 
Congregational schools struggle with time constraints. Informal settings such as camps or youth groups are often staffed primarily by part-time employees with little or no training; while they may be relatively free of typical academic expectations, they usually lack a robust conception of the kinds of learning that they aspire for their participants to achieve. Here we draw from our experiences in both general and Jewish educational settings to propose suggestions for how WCE efforts can become tightly integrated into the learning agenda of Jewish Education.

\section{Opportunities for Whole Child Jewish Education}

There are many opportunities within Jewish education to address whole child outcomes in ways that are both rooted in Jewish text and tradition and are validated by research. ${ }^{12}$ Consider the following six examples:

1. Exploration of the social and emotional elements of Jewish (classic and contemporary) texts and within Jewish history: Biblical narratives provide one of the most basic entry points to WCE in Jewish education. Study of the weekly Torah portion, a common activity, brings learners into dialogue with characters in emotion-laden situations. The family dynamics in the book of Genesis, for example, let us encounter a range of emotions (e.g., jealousy in the stories of Cain and Abel and of Joseph and his brothers). The array of material is as wide as the definition of "Jewish text," including Rabbinic stories as well as contemporary literature. Historical events, too, provide opportunity to develop cause-and-effect thinking, empathy, and perspective taking, all firmly rooted within academic Jewish studies.

2. Participation in tikkun olam ("repairing the world") activities: Research suggests that participation in social action or service learning projects can build a variety of social and emotional competencies. ${ }^{13}$ Many Jewish schools involve students in social action or service, under the banner of tikkun olam, throughout their

12 Maurice J. Elias et al., Promoting Social and Emotional Learning: Guidelines for Educators (Alexandria, VA: Association for Supervision and Curriculum Development, 1997); Joseph E. Zins et al., Building Academic Success on Social and Emotional Learning (New York: Teachers College Press, 2004).

13 Shelley Billig, "Research on K-12 School-Based Service Learning: The Evidence Builds," Phi Delta Kappan 81 (2000), 658-64. 
educational experience. These activities can take many forms, from fundraising for a local shelter to a group trip to help build houses in communities that have suffered a natural disaster. Some schools have a requirement that students volunteer for such activities on their own for a certain number of hours. The bar/bat mitzvah "project"framed as tikkun olam, or sometimes as a tzedakah (charity/justice), or mitzvah (commandment) project-has become commonplace. When service becomes service learning, the learning that takes place is not merely cognitive (e.g., learning about the causes of homelessness or about resources available to the mentally ill) but potentially encompasses the full range of social and emotional competencies.

3. Prayer: Though prayer is a central element of Judaism, prayer education poses multiple challenges to educators. Learners struggle to parse the complex liturgy and to master the choreography of formal prayer. Prayer, however, presents wonderful opportunities to address emotional and spiritual developmental elements. ${ }^{14}$ It can allow participants moments of individual reflection as well as shared emotional experiences.

4. Education in informal settings: To this point, we have been focusing on the school as the primary setting of Jewish education. It is also important to recognize non-school venues. Summer camps, particularly overnight camps, provide opportunities to grow skills in communal living and for self-exploration in a safe environment. The power of such settings emerges in large part in their providing an "encompassing" 15 Jewish experience interwoven with day-to-day "secular" activities.

5. Mussar, a Jewish approach to character development that emerged in Eastern Europe in the nineteenth century, is having a contemporary resurgence. This approach is notable in its overlap with core components of whole child education. Mussar involves (1) a focus on wellarticulated core middot (often translated as values or character traits, such as humility and patience); (2) reflective self-evaluation of one's strengths and needs with regard to these values; (3) action planning for behavioral change; and (4) tracking progress with the help of a group and through journaling. The middot are drawn from Jewish (primarily

14 Amy Walk Katz, "Teaching Tefillah," in What We Now Know about Jewish Education: Perspectives on Research for Practice, ed. Roberta Louis Goodman et al. (Los Angeles: Torah Aura Productions, 2008), 299-309.

15 Jeffrey S. Kress and Maurice J. Elias, "Distancing in Encompassing Education Settings: Lessons from Jewish Education," Journal of Applied Developmental Psychology 29, no. 4 (2008), 337-44. 
rabbinic) sources that often draw out nuances that are easy to overlook. Humility (anavah), for example, may be framed in terms of how much space one occupies in a situation. In this light, humility is not expressed only in terms of self-effacement and stepping back humbly, but also by stepping up and asserting one's self as needed. Perhaps because of the contemporary, self-help spin often given to the process, mussar study has taken root among diverse segments of the Jewish community. For example, adult mussar study groups have sprung up across the country $^{16}$ and school-based approaches, such as that developed by Rabbi David Jaffe ${ }^{17}$ brings mussar-based learning to educators and students.

6. Hevrutah learning is a traditional format of Jewish study in which pairs of students grapple with the meaning of texts. In contemporary Jewish education, hevrutah has been discussed as a venue in which learners can practice interpersonal communication - often taking the form of argumentation or debate - in the context of Jewish learning. ${ }^{18}$

\section{Developmental Process Theory as an Organizing Idea}

While these potential entry points exist, and creative whole-child work occurs regularly in Jewish schools, it has been our observation that there is seldom a structured, school-wide developmental plan for education in the socioaffective sphere. As such, the development-promoting experiences in schools often happen in isolation, as "one-offs," or as chance "teachable moments." 19 While these experiences can be impactful, they may not integrate deeply into the every-day life of the school, and they may fail to capitalize on the synergy that can emerge from a coordinated whole child approach. ${ }^{20}$

16 For example, Arielle Levites and Ira Stone, "Carrying the Burden of the Other: Musar and Adult Development," in Growing Jewish Minds, Growing Jewish Souls, ed. Jeffrey S. Kress (New York: URJ Press, 2013).

17 As described in Jeffrey S. Kress, "Learning from a Mussar-Based Initiative in a Jewish Community Day School," Journal of Jewish Education 83 no. 2 (2017), 133-50.

18 Elie Holzer, "What Connects 'Good' Teaching, Text Study and Hevruta Learning? A Conceptual Argument," Journal of Jewish Education 72, no. 3 (2006), 183-204; Orit Kent, "Interactive Text Study: A Case of Hevruta Learning," Journal of Jewish Education 72, no. 3 (2006), 205-32.

19 Jeffrey S. Kress, Development, Learning, and Community: Educating for Identity in Pluralistic Jewish High Schools (Brighton, MA: Academic Studies Press, 2012).

20 Stephanie M. Jones and Suzanne M. Bouffard, "Social and Emotional Learning in Schools: From Programs to Strategies,” SRCD Social Policy Report 26, no. 4 (2012), 3-22. 
As with any educational endeavor, developmental guideposts can help create a comprehensive longitudinal focus. There is a reason we do not introduce calculus to a second-grader or provide an adolescent with a children's book. Similarly, socio-emotional content has to be introduced with sensitivity to development, and skills have to be tied to a larger, whole-child emphasis that understands what children at different ages tend to be working on naturally. A new model, developed by the first author and colleagues, organizes the goals of WCE into four domains and has been used to help educators structure their efforts. ${ }^{21}$

Developmental Process Theory, also known as the Clover Model, uses the image of a clover to describe whole person development from childhood through adolescence. Each of the clover's four leaves reflect a particular kind and domain of development. ${ }^{22}$ The four leaves of the clover are (1) active engagement, (2) assertiveness, (3) belonging, and (4) reflection. These four dimensions and their interactions do not follow each other sequentially, but are each present at all points of development. Furthermore, the leaves are not orthogonal; rather they overlap like in a Venn diagram.

Each domain will be explained in further detail below, but first it is important to state that the purpose of this theory is to create the most simple and efficient set of constructs, basic frames, and needs that are present from the beginning of life and continue throughout. It is not hard to make out of the four dimensions eight, ten, or even forty as, for example, the asset model of Peter Benson ${ }^{23}$ and his colleagues have shown. The goal of the developers of this construct was not to divide and subdivide, but to seek the very minimum dimensions necessary to provide heuristic guidance to the efforts of those working with WCE.

Every individual employs all four of these developmental processes. At the same time, each domain takes prominence for specific age groups. People move along a continuum, prioritizing the task of one domain before another,

21 Gil G. Noam and Tina Malti, "Responding to the Crisis: RALLY's Developmental and Relational Approach," New Directions for Youth Development 2008, no. 120 (2008), 31-55; Gil G. Noam and Tina Malti, "Future Systemic Transformations," New Directions for Youth Development, 179-88; Gil G. Noam et al., "Social Cognition, Psychological Symptoms, and Mental Health: The Model, Evidence, and Contribution of Ego Development," in Developmental Psychopathology, 2nd ed., ed. Dante Cicchetti and Donald J. Cohen (Hoboken, NJ: John Wiley \& Sons, 2006).

22 Noam and Malti, "Responding to the Crisis," 31-55; Noam and Malti, "Future Systemic Transformations," 179-88.

23 Peter L. Benson, "Developmental Assets and Asset-Building Community: Conceptual and Empirical Foundations," in Developmental Assets and Asset-Building Communities: Implications for Research, Policy, and Practice, ed. Richard M. Lerner and Peter L. Benson (New York: Kluwer, 2003), 19-46. 
but that priority does not mean that the other dimensions are not applicable. In early adolescence, for example, the belonging dimension becomes essential. But the physical needs of the active engagement leaf, the issues of assertion (e.g., of will and trying to make an impact), and reflection about self and the world also are active. These establish a new balance with belonging as the preeminent developmental tension. This model preserves a developmental point of view while broadening the scope from a stage-wise progression of sense-making (Jean Piaget) or life tasks (Erik Erikson) or a singular focus on relationships (John Bowlby). Body, will, attachment, and cognition are in continuous exchange. They evolve together and apart, maintaining a tension between progression and regression.

Understanding this can help educators assess the strengths and risks posed by the particular developmental process facing youth of their students' age. The model's utility lies in its understanding of the balancing act among these four essential elements throughout development and can provide the underpinning of a whole child perspective.

Having explained the purpose in developing the theory, and how the developers understand what the theory does and does not represent, we can now turn to defining each of the leaves or domains (See Figure 1).

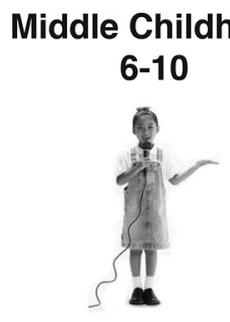

Pre-School

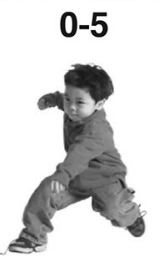

\section{od}
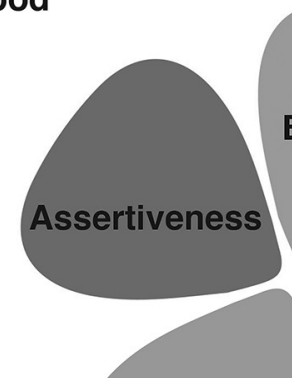

Active Engagement

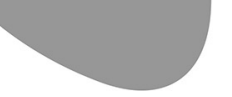

Reflection

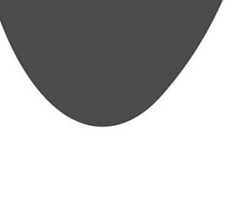

\section{Early Adolescence} 11-15

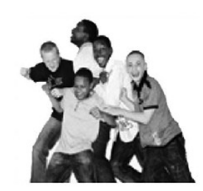

Full Adolescence

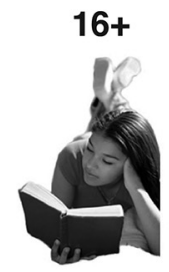

Figure 1: The Clover Model.

Active Engagement. The child in early childhood is often all about action, though this tends to be slightly more so for boys than girls. They need to be active, they think better when active, and they view the world in terms of 
concrete consequences of behavior. They are aware of and concerned with their own perspective, primarily, and with actively engaging in the world. Their goal is to learn about the world, experience mastery of different activities, and in doing so satisfy immediate needs. But time spent in action also helps youth learn about who they are and whom and what they like.

Assertiveness. Exploring their world is paramount for children, and to do this, they assert themselves, their wants and needs, and interests (now more verbally than via action). They can appear oblivious to the needs of others because they don't yet have the capacity to fully coordinate multiple perspectives. Learning to do so will require asserting themselves and dealing with the reactions of others. Of course, what they anticipate the reactions of others may be will be shaped - for better or worse - by attachment history as well as by their expectations for hostility or support from others, and their cognitive abilities. Knowing a youth may be expecting hostility from others and understanding aggressiveness in terms of striving for assertion may help a mentor normalize a mentee's aggressiveness ${ }^{24}$ and help the mentor provide a corrective emotional experience.

Belonging. With a secure attachment, a youth will explore the world with ease, and if the youth has successfully achieved mastery during his or her industrious explorations of talents, interests, and skills, both of these experiences will dovetail with the emergence of the mutual-inclusive perspective-taking skills that typically appear during the shift from middle to high school (sometimes earlier for girls). The result is a concern for belonging and a sense of allegiance with like-minded and affirming peers. A sense of belonging becomes all-important, such that peers take on magnified importance, sometimes trumping family connectedness as the youth's primary source of social-affirmation. Of course, too much concern with belonging can result in an overly conforming approach to peer relationships that limits self-exploration and can even handicap a youth whose potential could catapult him or her beyond the reaches of her peers academically or professionally.

Reflection. The teen who is able to take a perspective on his or her friendships, cultural group, or family, can begin to reflect on ways in which he or she differs from others, in values, potential, interests, and needs. A deeper degree of identity exploration can ensure with the full force of mutual-inclusive

24 Tina Malti and Gil G. Noam, "A Developmental Approach to the Prevention of Adolescent's Aggressive Behavior and the Promotion of Resilience," International Journal of Developmental Science 3, no. 3 (2009), 235-46. 
perspective taking being applied to self-discovery. Reflection, which is hampered by anxious attachment but helped by the security of solid attachment style, results in exploration beyond the comfortable boundaries of the collective views of peers, families, and other familiar people. Knowing this, a mentor can help the youth who wants (and now is able) to engage in deeper reflection to consider opportunities the youth has never considered.

As should be clear from this brief overview, children are not located within a particular domain to the exclusion of the other three. At each position on the clover, other leaves can take prominence for a brief or extended period, or in specific relationships or contexts. And the process of one leaf may be needed to bridge two others. For example, the transition from the belonging to reflection position may require an altogether new type of assertion to chart new educational territories or career terrain. Normative changes that occur from middle childhood to late adolescence mean that adolescents typically have different needs for belonging, assertion, action, and reflection than children. From a developmental perspective, it also means that significant relationships need to foster child and adolescent needs and thereby fill a unique function in the youth's life.

When educators talk about the whole child, or about socio-emotional learning, they typically list skills such as perseverance, teamwork, and critical thinking, the kind of twenty-first century tools that everyone needs to succeed. The Clover Model can provide a developmental frame within which to address core socio-affective skills (Figure 2).

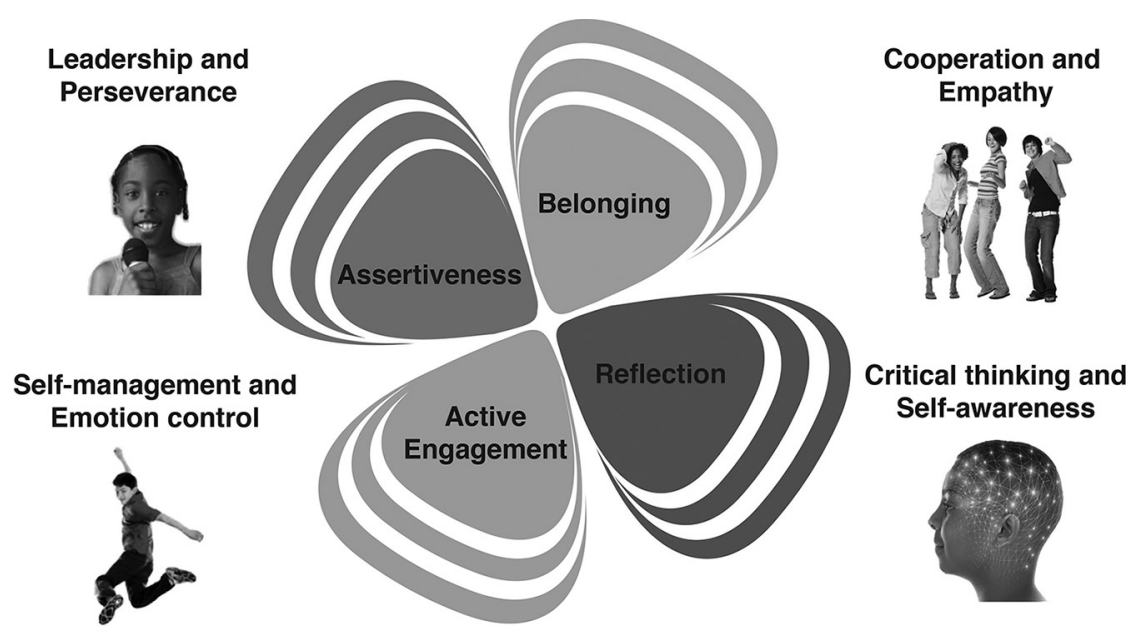

Figure 2: The Clover Model and Socio-emotional Skills. 
This model is used in educational settings as a translational language for teachers, mental health professionals, and afterschool providers to simplify communication. Notably, the use of the clover can help educators and others avoid falling into the prevalent language of psychopathology (e.g., this is an ADD, oppositional, depressed student).

\section{Assessment for Fostering WCE}

In a climate in which there is debate about the amount of "testing" to which students are subject, it may seem strange to bring assessment into the conversation about WCE. However, a structured approach to WCE assessment can help educators be proactive in addressing the socio-affecting needs of their students, and can provide the data needed to track the evolution of those needs over time. Because rigorous assessment can be done quickly via self-report, logistical challenges are minimized.

Numerous approaches and instruments have been developed to assess elements of socio-affective elements of development. ${ }^{25}$ Here, we discuss one of these, the Holistic Student Assessment (HSA), developed by the first author based on the Clover Model described above.

It might seem like a stretch to bring assessment into play; but it is not if we embrace a few premises:

- That student voice matters and that self-report is a short and fast way to ask for student feedback and self-evaluation.

- That the data are collected early in the school year so that it can inform teacher strategy and student support interventions.

- That the data are tied to strengths, so that they can be enlarged and brought to good use and that they also cover risk so socio-emotional support can be put in place to prevent mental health disorders.

- That results are only one way of collecting data, with the intuitive and relational aspects of teacher-student connection being at the fore.

\section{The Holistic Student Assessment (HSA)}

The HSA is a self-report containing sixty-one items and takes fifteen minutes to administer. It is administered to groups and always taken voluntarily with

25 Joseph Ciarrochi et al., "Measuring Emotional Intelligence," in Emotional Intelligence in Everyday Life: A Scientific Inquiry, ed. Joseph Ciarrochi et al. (New York: Psychology Press, 2001), 25-45. 
parental agreement. The results are confidential and schools and afterschool programs have the results back within a week. Typically, the assessment is administered at the beginning of the school year to "know every child" and to be able to build on the strengths and to reduce the vulnerabilities before a whole school year is lost. Typically a post assessment is administered to review changes (again, from the perspective of the students) at the individual, classroom, school, and even district levels. A short teacher version has been developed and a parent version is being piloted. Most of the HSA's scales (Table 1) are organized around the Clover Model. These scales fit into three domains: resiliencies, relationships to adults and with peers, and learning orientation.

HSA results are reported through the HSA Dashboard, an interactive visual interface that summarizes data for individual students and for groups. It is possible to go from individual students to whole classrooms to support the teacher in understanding patterns of an entire class. One can also aggregate up to the whole school with a possibility to create a school-wide dashboard for planning and evaluation. Results can be discussed with individual students and learning plans developed accordingly.

Table 1: HSA Subscales

- Action Orientation: Assesses the respondent's level of activeness, physical activity, and physical engagement.

- Emotional Control: Measures the respondent's emotional control, self-discipline, and self-control. These two scales make up the Active Engagement Clover.

- $\quad$ Perseverance: Evaluates one's willingness to work hard and solve problems despite obstacles and challenges.

- Assertiveness: Examines the participant's level of comfort in advancing their own personality, beliefs, wishes, or thoughts, and whether one has the confidence to stand up for what one believes is fair. These two scales make up the Assertive Clover.

- $\quad$ Trust: Considers one's level of trust and vulnerability to the actions of others and one's confidence that others will support them when called upon.

- $\quad$ Empathy: Assesses the ability to recognize and share in the feelings of others, and one's initiative to help others and improve surroundings. 


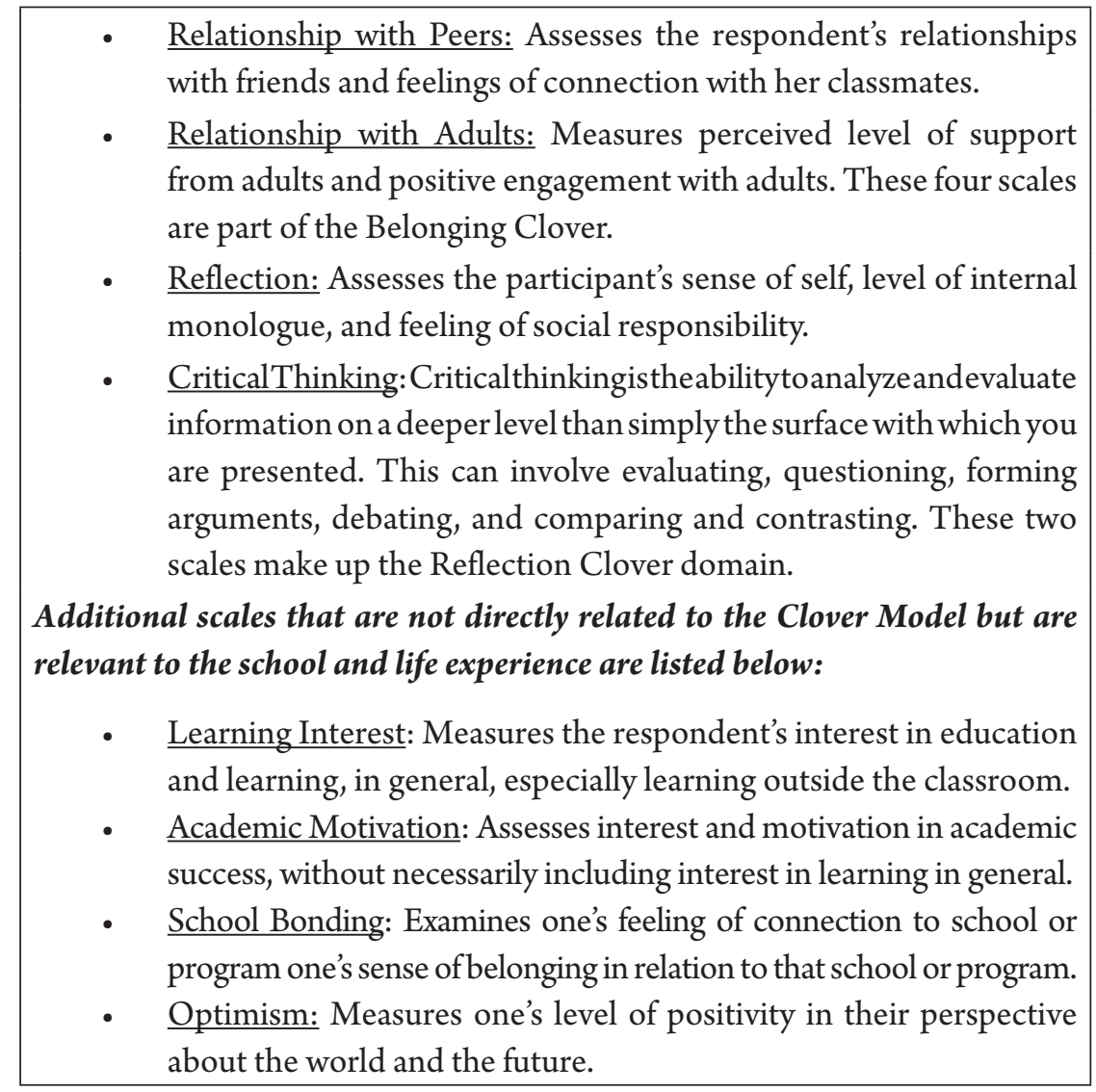

\section{A Case Example}

We will describe a fifth-grade girl and her assessment to further illustrate the utility of the instrument and the potential use in a Jewish education context. When looking at her HSA results, shown in Figure 3, we can see that this student has a balance of five strengths and five challenges. In the learning and school engagement section, this girl scores above the norm on every scale, with strengths in Learning Interest and Academic Motivation. Based on her selfreported strengths in academics, this student most likely is a successful student in the classroom. But when we look at the Resiliencies and Relationships scales, we see that she has some challenges that may not be apparent to the teacher, specifically in Assertiveness, Trust, Optimism, and Relationships with Peers. These challenges, when found together particularly with her high Reflection and academic strengths, speak of a student who is internalizing her challenges 
and struggling in her relationships with others. This struggle leads to a lack of Optimism and Trust. The good news is that this girl does not need a clinical intervention, but reorganization in the classroom structure to give her a peer leadership role to strengthen her assertiveness. She could benefit from a summer or afterschool program that allows and encourages students to have a voice. These kinds of preventative measures could help to address some of the internal struggles of an otherwise strong and successful student.

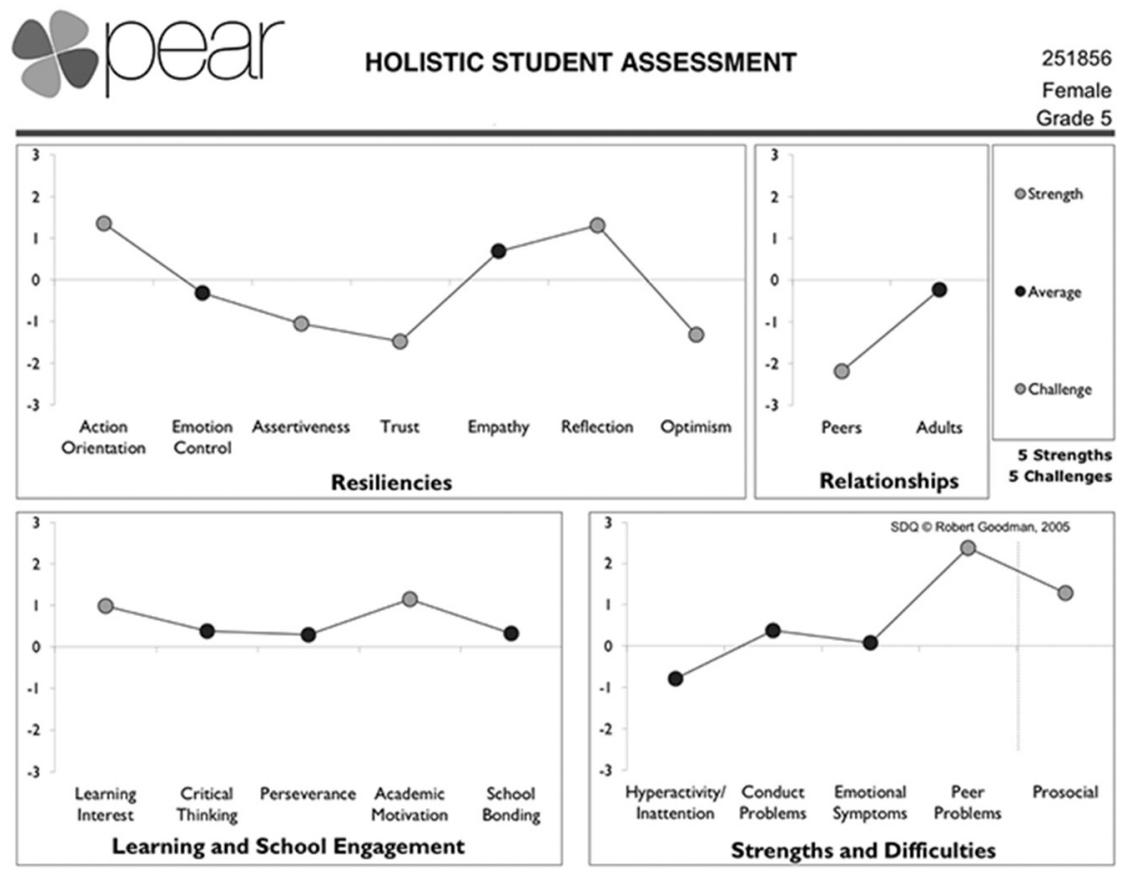

Figure 3: Sample HSA Individual Portrait.

Jewish schools can benefit greatly from this type of information. It is not very expensive to set up this system and to provide information and coaching to educators. This approach also allows for developing and adding scales that are important to specific educational goals without losing one of the main benefits: That at all times it is possible to compare one classroom to another and to always review data compared to a national normative sample.

We have discussed the HSA in relationship to schools and classrooms, but it can also be used in Jewish afterschool and summer settings, where limited contact hours and staff educators with less training often make it difficult to assess students' strengths and needs. The fact that the HSA is easily 
administered and gets scored centrally and inexpensively with individual and group results clearly graphed makes use in supplemental and informal settings very possible.

\section{Whole Child Assessment in Jewish Education}

As discussed above, the idea of whole person education is deeply ingrained within the project of Jewish education. Outcomes in the socio-affective realm should be approached with at least the same degree of intentionality as other outcomes. We see this as part of a trend in Jewish education toward taking outcomes seriously and "backward planning" toward their achievement. Accountability and assessment have increasingly taken the spotlight in communal discussions of Jewish educational policy. ${ }^{26}$ The "Standards and Benchmarks" project undertaken by the Davidson Graduate School of Jewish Education with funding from the AVI CHAI and Legacy Heritage Foundations and others, is an example of this planful intentionality. Specific goals and outcomes have been articulated for Bible education, and are currently being developed for Rabbinics education. Importantly, socio-affective elements are interwoven throughout.

Assessment in the WCE sphere can and should be done in the spirit of deepening our knowledge of each learner as an individual, allowing our education and engagement efforts to be best targeted to better leverage their strengths, and address their needs. ${ }^{27}$ While this deep knowledge would be important to any educator, it could be particularly useful as an efficient way of gathering information in those settings with limited contact hours. Knowing the social and emotional profiles of learners would allow time and resources to be targeted appropriately. One can imagine a social and emotionally based differentiated instruction in which, for example, "action-oriented" learners are provided with hands-on activities while those high on "reflection" are offered additional opportunities for making personal connections. Educators working in informal settings, particularly immersive ones, could benefit from information

26 For example, Chip Edelsberg, "Are You High Performance? Leap of Reason Can Help You Answer 'Yes!' Jim Joseph Foundation, published March 11, 2015. https://jimjosephfoundation.org/high-performance-leap-reason-can-help-answer-yes/.

27 Jim Joseph Foundation, "Effective Strategies for Educating and Engaging Jewish Teens," Jim Joseph Foundation, BTW Informing Change, Rosov Consulting, March 2013, http://jimjosephfoundation.org/wp-content/uploads/2013/03/Report_and_Appendix_Effective_ Strategies_for_Educating_and_Engaging_Jewish_Teens.pdf. 
that allows them to proactively address the social and emotional competencies needed by participants to navigate these complex environments.

While Jewish educational settings often have whole child growth at the core of their missions, there are notable challenges to implementing our recommendations with regard to structured assessment. We do not present our ideas as a "how-to manual," but rather a call to the field for creative approaches, even given challenges of logistics, funding, etc. A first step involves being willing to grapple with these challenges. The application of these ideas to different Jewish educational settings should be explored. For example, on the surface, the idea of structured assessment may seem counter to the culture of informal settings such as camps and youth groups. However, if such an assessment can help these settings achieve their whole-person developmental goals, then they ought to consider how it might be incorporated into practice. This is not impossible; even a broad survey of these issues can provide a camp with a profile of programmatic strengths and needs. ${ }^{28}$

One may also wonder if assessment can really capture the complex intraand inter-personal outcomes of Jewish education. Of course, any measure will fall short of capturing the richness of the human experience for which it is a proxy. We recommend taking such approaches for what they are-tools to help concretize a complex set of outcomes in order to enhance practice-and not to reify the outcomes.

Inroads have been made in this regard within Jewish educational settings, illustrating the potential for a more structured approach to assessment. For example, Melissa Werbow and Yael Silk challenge us to "Imagine a world in which religious schools don't just work toward goals like inspiring a love of Jewish learning, but also assess their classrooms to determine if they are achieving their goals." 29 These educators take concrete steps toward achieving this vision by developing a rubric by which to analyze Jewish learning. Notably, this rubric encompasses the sort of socio-affective elements at the core of whole child education. For example, they capture the notion of seeking wisdom through observing the questions asked by students.

28 For example, Jeffrey S. Kress and Michael Ben-Avie, "Social Climate at Ramah: Relationships and Motivation," in Ramah at 60: Impact and Innovation, ed. Mitchell Cohen and Jeffrey S. Kress (New York: National Ramah Commission, 2010), 143-58.

29 Melissa Werbow and Yael Silk, "All You Need is Love... And A Rubric." eJewish Philanthropy, Published November 24, 2013, http://ejewishphilanthropy.com/all-you-need-is-love-anda-rubric/. 
A behavioral-criterion approach was also used by second author in his work with a mussar-based character education program developed by Rabbi David Jaffe, with support from the Covenant and AVI CHAI Foundations, for use at the Gann Academy in Waltham, Massachusetts. ${ }^{30}$ Participants in this program focused on monthly middot, perhaps best translated here as character traits. As part of the assessment of the initiative, we linked focal middot with behavioral indices related to the work of the school administrators (our pilot group for this self-rating). With savlanut (patience) for example, participants were asked to self-rate whether "I tend to respond to stressors without fully thinking things through." One can imagine a sort of 360-degree middah indicator assessment.

We also call for further work linking WCE concepts with Jewish texts and ideas, so that whole child efforts can permeate Jewish educational settings. Existing examples include Jonathan Cohen's work linking each of the Search Institute's 40 Developmental Assets with a Jewish value or ideal ${ }^{31}$ and the Open Circle Program's initiative to link social and emotional competencies with Jewish texts. ${ }^{32}$ Further work in this area will help create an infusion of authentic Jewish concepts with research-validated whole person learning approaches.

Finally, as we noted previously, WCE focuses on both socio-affective competencies and also the climate in which education takes place. While this chapter has focused on the former, it is worth noting that class and school climate have been measured in various ways in Jewish educational contexts. For example, Ian Cohen, Jeffrey Kress, and Maurice Elias ${ }^{33}$ used student self-report to assess class climate and Michael Ben-Avie and Kress assessed school climate as reported by teachers ${ }^{34}$ and camper climate as reported by campers. ${ }^{35}$

30 Kress, "Learning from a Mussar-Based Initiative," 133-50.

31 These had been previously posted on the Search Institute's website and can now be found reported to http://www.chabadpw.org/templates/articlecco_cdo/aid/444694/jewish/40Developmental-Assets.htm.

32 Shoshana Simons and Ruth Gafni, "Fine-Tuning the Listening Heart: Weaving Together the Teaching of Jewish Ethics and Socio-Emotional Learning through the Open Circle Program," in Kress, Growing Jewish Minds, 85-100.

33 Ian J. Cohen et al., "Classroom Climate in an Orthodox Day School: The Contribution of Emotional Intelligence, Demographics, and Classroom Context," Journal of Jewish Education 68, no. 1 (2002), 21-33.

34 Michael Ben-Avie and Jeffrey S. Kress, A North American Study of Educators in Jewish Day and Congregational Schools: Technical Report of the Educators in Jewish Schools Study (Jewish Educational Change, N.d.).

35 Kress and Ben-Avie, "Social Climate at Ramah," 143-58. 


\section{Conclusion}

This chapter addresses a number of interconnected issues. First, we wanted to call attention to a shift occurring in this country toward a more holistic approach in education with such diverse constituencies as community education, character and moral development, and social-emotional learning. Second, it was our goal to show that there is a great deal of foundational thinking about these topics in Jewish education supporting a whole child view. Third, we introduced the Clover Model as one way to simplify this wide variety of theories and concepts and ideas so that teachers, parents, and students can make sense of the psychological and developmental mission and goals relating to whole child education. Next, we wanted to show that assessment can be used to improve the quality of whole child learning in a school or other educational setting, to help adults support the healthy development of children and youth, and to prevent negative outcomes educationally, psychologically, and socially. As a final step, we discussed the use of these systems in Jewish schools and how we believe that these schools should open themselves to more data guidance.

The most important point underlying all of our ideas is this: socio-emotional life is an essential part of Jewish identity and ought to be central to the articulated and pursued learning outcomes in Jewish education. Jewish pride, suffering, survival under hugely adverse conditions, the role of stories and humor, family celebrations, and the study of the Bible with all its deep wisdom about living a whole life embedded in the community-all of this is socioemotional development and learning. We have research to support these ideas in secular forms. As Jewish educators, we ought to broaden our perspectives and hone our skills to educate children and youth to be sensitive, empathic, ethical, and intellectually skilled and curious people - that is, to be whole people and whole Jews. 


\section{Bibliography}

Association for Supervision and Curriculum Development. Making the Case for Whole Child Education. Alexandria, VA: ASCD, 2012.

Ben-Avie, Michael, and Jeffrey Kress. A North American Study of Educators in Jewish Day and Congregational Schools: Technical Report of the Educators in Jewish Schools Study. Jewish Educational Change. Accessed (November 12, 2017). www.jewishdatabank.org/studies/ downloadFile.cfm?FileID=2708.

Benson, Peter L. "Developmental Assets and Asset-Building Community: Conceptual and Empirical Foundations." In Developmental Assets and Asset-Building Communities: Implications for Research, Policy, and Practice. Edited by Richard M. Lerner and Peter L. Benson, 19-46. New York: Kluwer, 2003.

Billig, Shelley. "Research on K-12 School-Based Service Learning: The Evidence Builds." Phi Delta Kappan 81 (2000), 658-64.

Buber, Martin. The Way of Man According to the Teaching of Hasidism. New York: Citadel Press, 1964. Ciarrochi, Joseph, Amy Chan, Peter Caputi, and Richard Roberts. "Measuring Emotional Intelligence." In Emotional Intelligence in Everyday Life: A Scientific Inquiry. Edited by Joseph Ciarrochi, Joseph P. Forgas, and John D. Mayer, 25-45. New York: Psychology Press, 2001.

Cohen, Ian J., Jeffrey S. Kress, and Maurice J. Elias. "Classroom Climate in an Orthodox Day School: The Contribution of Emotional Intelligence, Demographics, and Classroom Context." Journal of Jewish Education 68, no. 1 (2002), 21-33.

Edelsberg, Chip. “Are You High Performance? Leap of Reason Can Help You Answer 'Yes!” Jim Joseph Foundation, published March 11, 2015. https://jimjosephfoundation.org/high-performance-leap-reason-can-help-answer-yes/.

Elias, Maurice J., Sarah J. Parker, V. Megan Kash, and Ed Dunkeblau. "Socioemotional Learning and Character and Moral Education in Children: Synergy or Fundamental Divergence in Our Schools?" Journal of Research in Character Education 5, no. 2 (2007), 167-182.

Elias, Maurice J., Joseph E. Zins, Roger P. Weissberg, Karin S. Frey, Mark T. Greenberg, Norris M. Haynes, Rachael Kessler, Mary E. Schwab-Stone, and Timothy P. Shriver. Promoting Social and Emotional Learning: Guidelines for Educators. Alexandria, VA: Association for Supervision and Curriculum Development, 1997. 
Fox, Seymour. "Ramah: A Setting for Jewish Education." In The Ramah Experience: Community and Commitment. Edited by Sylvia C. Ettenberg and Geraldine Rosenfield, 19-37. New York: Jewish Theological Seminary and National Ramah Commission, 1989.

Fox, Seymour, and William Novak. Vision at the Heart: Lessons from Camp Ramah on the Power of Ideas in Shaping Educational Institutions. Jerusalem and New York: The Mandel Institute and The Council for Initiatives in Jewish Education, 1997.

Fox, Seymour, Israel Scheffler, and Daniel Marom. "Six Visions: An Overview." In Visions of Jewish Education. Edited by Seymour Fox, Israel Scheffler, and Daniel Marom, 19-43. Cambridge: Cambridge University Press, 2003.

Fox, Seymour, Israel Scheffler, and Daniel Marom. Visions of Jewish Education. Cambridge: Cambridge University Press, 2003.

Holzer, Elie. "What Connects 'Good' Teaching, Text Study and Hevruta Learning? A Conceptual Argument." Journal of Jewish Education 72, no. 3 (2006), 183-204.

Jim Joseph Foundation. "Effective Strategies for Educating and Engaging Jewish Teens: What Jewish Communities Can Learn from Programs that Work.” Jim Joseph Foundation, BTW Informing Change, Rosov Consulting. March 2013. http://jimjosephfoundation. org/wp-content/uploads/2013/03/Report_and_Appendix_Effective_Strategies_for_ Educating_and_Engaging_Jewish_Teens.pdf.

Jones, Stephanie M., and Suzanne M. Bouffard. "Social and Emotional Learning in Schools: From Programs to Strategies." SRCD Social Policy Report 26, no. 4 (2012), 3-22.

Kaplan, Mordecai M. Judaism as a Civilization: Toward a Reconstruction of American-Jewish Life. $2^{\text {nd }}$ ed. Philadelphia: Jewish Publication Society, 2010.

Katz, Amy Walk. “Teaching Tefillah." In What We Now Know about Jewish Education: Perspectives on Research for Practice. Edited by Roberta Louis Goodman, Paul A. Flexner, and Linda Dale Bloomberg, 299-309. Los Angeles: Torah Aura Productions, 2008.

Kent, Orit. "Interactive Text Study: A Case of Hevruta Learning." Journal of Jewish Education 72, no. 3 (2006), 205-32.

Kress, Jeffrey S. Development, Learning, and Community: Educating for Identity in Pluralistic Jewish High Schools. Brighton, MA: Academic Studies Press, 2012.

"Learning from a Mussar-Based Initiative in a Jewish Community Day School." Journal of Jewish Education 83 no. 2 (2017): 133-50

Kress, Jeffrey S., and Michael Ben-Avie. "Social Climate at Ramah: Relationships and Motivation." In Ramah at 60: Impact and Innovation. Edited by Mitchell Cohen and Jeffrey S. Kress, 143-58. New York: National Ramah Commission, 2010.

Kress, Jeffrey S., and Maurice J. Elias. "Distancing in Encompassing Education Settings: Lessons from Jewish Education." Journal of Applied Developmental Psychology 29, no. 4 (2008), 337-44.

Levites, Arielle, and Ira Stone. "Carrying the Burden of the Other: Musar and Adult Development." In Growing Jewish Minds, Growing Jewish Souls. Edited by Jeffrey S. Kress. New York: URJ Press, 2013. 
Malti, Tina, and Gil G. Noam. "A Developmental Approach to the Prevention of Adolescent's Aggressive Behavior and the Promotion of Resilience." International Journal of Developmental Science 3, no. 3 (2009), 235-46.

Noam, Gil G., and Tina Malti. "Future Systemic Transformations." New Directions for Youth Development, no. 120 (2008), 179-88.

Noam, Gil G., and Tina Malti. "Responding to the Crisis: RALLY's Developmental and Relational Approach.” New Directions for Youth Development, no. 120 (2008), 31-55.

Noam, Gil G., Copeland H. Young, and Janna Jilnina. "Social Cognition, Psychological Symptoms, and Mental Health: The Model, Evidence, and Contribution of Ego Development." In Developmental Psychopathology, 2nd Edition. Edited by Dante Cicchetti and Donald J. Cohen. Hoboken, NJ: John Wiley \& Sons, 2006.

Shulman, Lee S. "Pedagogies of Interpretation, Argumentation, and Formation: From Understanding to Identity in Jewish Education." Journal of Jewish Education 74, sup. 1 (2008), 5-15.

Simons, Shoshana, and Ruth Gafni. "Fine-Tuning the Listening Heart: Weaving Together the Teaching of Jewish Ethics and Socio-Emotional Learning through the Open Circle Program." In Growing Jewish Minds, Growing Jewish Souls. Edited by Jeffrey S. Kress, 85-100. New York: URJ Press, 2013.

Werbow, Melissa, and Yael Silk. "All You Need is Love ... And A Rubric." eJewish Philanthropy. Published November 24, 2013. http://ejewishphilanthropy.com/all-you-need-is-love-anda-rubric/.

Zins, Joseph E., Roger P. Weissberg, Margaret C. Wang, and Herbert J. Wallberg. Building Academic Success on Social and Emotional Learning. New York: Teachers College Press, 2004. 